\title{
Research on the Influence Mechanism of Music Education on College Students' Innovative Thinking
}

\author{
Donglan Li \\ Professor from School of Arts, Guangdong University of Foreign Studies \\ Daxue Cheng Campus, Guangzhou City, 510006, Guangzhou, China
}

\begin{abstract}
The cultivation of innovative talents has always been an important strategic goal in the field of education. Creation is deemed as the basis of innovation. Especially for the cultivation of college students' innovative ability, thinking is the most important cognitive process to promote creativity, while divergent thinking is at the core of innovation ability. With the "creativity" theory proposed by Guilford as the theoretical basis of this article, an empirical test was carried out for the operable educational program devoted to the cultivation of innovative thinking proposed by him. It proves that music has a certain relationship with divergent thinking ability in innovative education. This conclusion provides a new way to explore and cultivate innovative talents in a more scientific way.
\end{abstract}

Keywords: Music education, Innovative thinking, Influence Mechanism

DOI: $10.7176 / \mathrm{JEP} / 10-3-17$

\section{Statement of Problem}

Creativity is the process of producing originality and value (Amabile et al., 1996).In the early days, the academic community explored creativity from personal traits (Cummings and Oldham, 1997), arguing that creativity should be a subconscious activity of interaction between ID and Superego, and that the motivation for creativity is derived from innate endowment. Creativity is a product of novel and useful ideas (Mnaumford and Gustafson, 1988). American psychologist Gilford is mainly engaged in creativity research. He believes that the main component of creativity is divergent thinking, that is, a comprehensive and unrestricted way of thinking about problems. He believes that divergent thinking has four characteristics, namely, fluency, flexibility, originality and elaboration, which have also become the main basis for judging whether an individual is creative (J.P. Guilford, 1967). Later, many scholars also pointed out that creativity is obviously not a simple concept, which cannot be fully explained by a single personality trait. Individual creativity should reflect the composite state of both cognition and affection (Willams, 1979). The part of affection refers to the emotion of a person. Music has an effect on improving mood for college students. Although early researches have shown that workplaces with musical backgrounds can improve the working environment and increase productivity (Keer, 1942 \& 1943a, 1971). However, these studies have not been applied to study the creativity of college students. In addition to the strong influence of creativity on individual personality traits, it is also inseparable from the influence of moods and emotions. Therefore, if empirical analysis reveals that music can stimulate the creativity and alleviate the pressure of college students, then this research will play an important reference role in cultivating college students' creativity.

Therefore, this study mainly explores how different kinds of music influence students' emotions, and ultimately influence the process of college students' innovative thinking. Specifically, we mainly study two issues. Firstly, we explore the relationship between the characteristics of music and emotions. Secondly, we explore whether different musical moods and environments can exert different influences on the innovative thinking ability of college students, so as to provide effective suggestions for cultivating college students' innovative thinking ability.

\section{Literature Review}

2.1 Introduction to the Concept

The characteristics of music: The diversity of music in form is closely related to our emotions. Featuring richness and diversity, music is a very complex structure. According to the applied characteristics of music, we divide the feeling of music into two parts: music and instrument. Music comprises melody and rhythm in music theory; and instrument is mainly expressed as volume. Therefore, the main components of music are melody, rhythm, tone and volume.

Emotional division: In general, positive emotions are characterized by enthusiasm, action, and alertness; while negative emotions are characterized by anger, disgust, guilt, fear, and tension. However, the two kinds of emotions are not completely isolated, and they include different degrees of arousal. Therefore, in addition to positive and negative emotions, emotions are divided into two levels: High arousal and low arousal, and there are four musical emotions. The details are as shown below: 
Table 1. Levels of musical emotions

Independent variable

\begin{tabular}{|c|c|c|}
\hline Valence & Arousal & Divergent thinking \\
\hline \multirow{2}{*}{$(\mathrm{V}+)$ Positive emotions } & \multirow{2}{*}{$\left(\mathrm{A}_{\mathrm{H}}\right)$ High arousal } & Fluency \\
\hline & & Flexibility \\
\hline \multirow{2}{*}{ (V-) Negative emotions } & \multirow{2}{*}{$\left(A_{L}\right)$ Low arousal } & Originality \\
\hline & & Elaboration \\
\hline
\end{tabular}

Divergent thinking: As an important ability and performance of college students in the process of innovative thinking, divergent thinking belongs to a part of the human mind structure. American psychologist Guilford has long been engaged in the study of human intelligence, and his speech about "creativity" published in 1950 was considered to be the beginning of a comprehensive study of creative science. He then conducted a detailed analysis of creativity and devoted himself to establishing a human intelligent construction model, used three dimensions to represent the structure of intelligence, and proposed the "intellectual three-dimensional structure" model (Guilford, 1967, P139).The main point is that human intelligence produces innovation through multiple factors of three-dimensionality, and divergent thinking belongs to a kind of psychological production in the mental structure. The process of thinking is the most important component of creativity, and the ability of divergent thinking is closely related to the ability to innovate. Therefore, divergent thinking plays a very important role in creativity, and this view has also been supported by many studies. Later, he conducted a more in-depth analysis of divergent thinking, and proposed that divergent thinking has four main characteristics, namely, fluency, flexibility, originality and elaboration. Fluency mainly represents the ability to generate a large number of ideas, and the more ideas, the more flexible the thinking. Flexibility refers to that an individual can think flexibly from different angles and directions. It is an ability to change the direction of thought and can be calculated by the number of proposed solutions. Originality mainly emphasizes the distinctiveness of ideas and unusualness of problem-solving ideas. It has novel and peculiar characteristics and can be judged from the way of dealing with problems. Elaboration (exquisiteness) focuses on the specific details of a thing or event, that is, the ability to modify and enhance a concept or product. From the process of solving the problem, we can judge the ability to think about the problems in a comprehensive and detailed manner.

\subsection{The Composition of Music and the Induction and Reorganization of Emotional Reactions}

The philosopher Plato once said that "music is to the mind what air is to the body." Music can enable people to adjust their mental state through changes in feelings and moods. Music evokes people's feelings with melody, stimulates people's emotions, inspires people's spirit with rhythm, uplifts people's morale, creates different feelings with different combinations of intervals and touches people with beautiful sounds, so the elements of music are closely related to emotional reactions and feelings of human beings. During a music playback, people will feel the level, strength, weakness, and length of the sound as well as the tone characteristics. The source of sound and people's familiarity with music will cause people to have different emotional changes, associations and memories. Ultimately, it has a physical and psychological impact on people. Music can influence people's psychological and physiological responses. The transmission is mainly realized by the sound waves of music, that is, the auditory nerves are stimulated via vibration, and then the auditory center in the brain is stimulated to feel the music. When the external stimulation of the human body is felt by the sensory organs, the peripheral nervous system is transmitted to the cerebral cortex to affect the human's psychological emotions on the one hand; on the other hand, the surrounding nervous system also affects the muscle movement and internal organs of the human body. According to the study of brain wave science, brain waves are divided into four wave domains according to frequency. They are alpha wave, beta wave, theta wave, and delta wave. The alpha wave is a regular and coordinated brain wave, and it happens when the human body is in a relaxed and calm state of consciousness and a sober eye-closing period. This state helps to improve people's creativity and enhance their memory. In the beta wave state, people have concentrated attention but negative emotions are generated. In the Theta wave state, the body will enter into a state of meditation and creation. In the Delta wave state, the body will experience deep sleep, deep meditation, and unconsciousness. From the above we can see that there is an interactive relationship between the psychological and physiological induction caused by the stimulation of music and the human body. 
Table 2 Music Components and Emotional Reactions

\begin{tabular}{|c|c|c|}
\hline $\begin{array}{l}\text { Music } \\
\text { Components }\end{array}$ & Definition & Emotional Reactions \\
\hline Melody & $\begin{array}{l}\text { The level of the sound is } \\
\text { determined by the rise or fall of a } \\
\text { single note, and the rhythm makes } \\
\text { regular horizontal change with the } \\
\text { passage of time. }\end{array}$ & $\begin{array}{l}\text { 1. Treble is more pleasant than bass } \\
\text { 2. The rise in tone gives the impression of going out } \\
\text { and leaving; the lowering of the tone gives the } \\
\text { impression of coming in and coming back. }\end{array}$ \\
\hline Interval & $\begin{array}{l}\text { The relationship between the two } \\
\text { levels of pitch refers to the } \\
\text { distance between the two tones on } \\
\text { the pitch, and it is expressed in } \\
\text { degrees. }\end{array}$ & $\begin{array}{l}\text { 1. The harmonious interval gives a perfect and } \\
\text { pleasant feeling, and the discordant interval is easy } \\
\text { to cause the emotional reaction of the "mystery". } \\
\text { 2. The sense of balance between the intervals makes it } \\
\text { easy to soothe the emotions, and the unbalanced } \\
\text { intervals form tension. }\end{array}$ \\
\hline Mode & $\begin{array}{l}\text { Several tones follow a specific } \\
\text { interval system, and center on one } \\
\text { tone. This system is called mode. }\end{array}$ & $\begin{array}{l}\text { 1. The major tone is lively, energetic, with positive } \\
\text { emotions. } \\
\text { 2. In most cases, the minor tone reflects negative and } \\
\text { sad emotions. }\end{array}$ \\
\hline Rhythm & $\begin{array}{l}\text { The time scale on the musical } \\
\text { form, indicating the length of the } \\
\text { note in time. }\end{array}$ & $\begin{array}{l}\text { 1. When the rhythm is clear and tough, it makes you } \\
\text { feel excited and uptight. } \\
\text { 2. The smooth and light rhythm creates a naughty, fun } \\
\text { and relaxed mood. Slow rhythm can relax and } \\
\text { soothe emotions. }\end{array}$ \\
\hline Tone & $\begin{array}{l}\text { It varies depending on the } \\
\text { vibration of different shapes, in } \\
\text { which the waveform and the } \\
\text { amplitude, time, and number of } \\
\text { vibrations constitute different } \\
\text { vibration shapes, and different } \\
\text { timbres are formed. }\end{array}$ & $\begin{array}{l}\text { 1. The tone of the copper tube makes people feel } \\
\text { indifferent, and the tone of the reed makes people } \\
\text { feel so lonely. } \\
\text { 2. The tone of the piano makes people feel calm. } \\
\text { 3. The sound of the strings makes people feel happy. } \\
\text { 4. The timpani makes people feel profound and the } \\
\text { snare makes people feel refreshing. }\end{array}$ \\
\hline Volume & $\begin{array}{l}\text { The intensity of the sound } \\
\text { depends on the pressure exerted } \\
\text { by the sound waves on the inner } \\
\text { ear nerve cells, usually expressed } \\
\text { in decibels. }\end{array}$ & $\begin{array}{l}\text { 1. The loud volume makes people feel energized, } \\
\text { while the low volume makes people feel calm. } \\
\text { 2. When the volume is turned from small to large, the } \\
\text { feeling is enhanced, and when the volume is turned } \\
\text { from small to large, the feeling is weakened. }\end{array}$ \\
\hline
\end{tabular}

\subsection{The Relationship between Emotion and Divergent Thinking}

Sternberg and Lubart (1995) pointed out that the vast majority of creative people are engaged in things that they are interest in and like to do, and this motivation is implicit. In most cases, the innovative ability of college students is reflected in creativity. For example, alternative thinking, subverting traditions, and pursuing novelty or whimsicality are all creativities. The source of creativity is thinking. Thinking can be divided into two categories, divergent thinking and convergent thinking. Divergent thinking breaks through the traditional linear thinking mode, and it is especially a highly-needed ability for college students to innovate. Apart from the reorganization of experience and knowledge, creative thinking also requires the inner creative motives of the human mind. The aspect of emotions and feelings is one of the important factors that influence creativity.

When conducting divergent thinking, the stimulation of musical emotions affects the development of creativity. By exploring the antecedents affecting emotions, as well as the consequences of different emotions or differences in behavioral performance, a new perspective and method is provided for us to study the divergent thinking ability of college students.

Barara Clark (1988) pointed out that isolated thinking activity could not give full play to high-level human creativity, and factors such as affection, feeling, and intuition are important links in the formation of creative thinking. Through research and analysis of the ideological activities that occur during human invention, Gordon (1944) proposed that when engaging in creative behavior, emotional factors are more important than intellectual factors, and that irrational factors are more important than rational factors. In 1988, Clark synthesized these theories of creativity and categorized them into four dimensions: Rational thinking, high emotional development, special talents, high levels of physical and mental development and high levels of ideology. Luban \& Getz (1977) argues that creativity comes from the interaction among personality traits, motivation, social environment and cognitive reorganization, and emotional and affectional variables are potential key variables of creativity. 


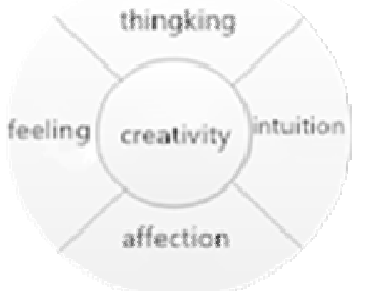

Creativity circle (Barbara Clark, 1988)

As mentioned above, we divide emotions into four levels. However, scholars have not drawn consistent conclusions with regard to the influence of positive and negative emotions on creativity. Some scholars believe that positive emotions can help to foster an individual's creative performance, and the relaxed and warm emotions can have a positive impact on people's creative performance (0'Quin\&Derks). The reason is that positive emotions can enable people's stimulated emotional activities to interact with the their cognitive activities, thus enhancing their cognitive attention, association, resilience, and elaboration (exquisiteness), and they are therefore able to see similarities and differences between things and excel others in creative thinking and performance (Ien \& Daubman, 1984).For example, Isen \& Daubman (1984) found in the experimental results that the group with positive emotion was more creative. Hirt (1995) found that positive emotion groups had better fluency in oral expression than subjects in the control group. Some scholars have studied from a biological point of view, believing that positive emotions can increase the activity of dopamine in the brain, and promote the selection of cognitive flexibility and cognitive choices. This theory explains why positive emotions strengthen cognitive activities such as smell and memory, and enhance creative thinking and problem solving.

Other scholars believe that the influence of negative emotions on creative thinking is more complicated, and there is no consistent conclusion between scholars regarding the performance of negative emotions and individual creativity. Some scholars have found that negative emotions can enhance individual creative performance (Tighe, 1992; Martin \& Stoner, 1996; George \& Zhou, 2002), while others argue that negative emotions have a negative impact on creative performance (Isen, 1985). This is mainly because that most of the emotions are input from outside, and when an individual is in a positive emotional state, it is easy for him/her to satisfy with the status quo and reduce the willingness to work. Conversely, negative emotions make people aware of the problem, motivate them to change, and therefore they are willing to put more effort into innovation. We can see that the impact of negative emotions on creative thinking may involve interactions between many other factors, and negative emotions are more complex than positive emotions.

By combing through the above literature, we know that there is a correlation between the components of music and emotional responses, but under different control environments and standards, this correlation may be different. This article uses experimental methods for measurement and verification based on the premise that there are regular links between different musical attributes and human emotions. That's why this article firstly explores whether people have consistent emotional responsiveness to different rhythms or melodies. Then, on this basis, the article differentiates the music that generates positive and negative emotions for people. Finally, we further explores whether emotions have different effects on divergent thinking.

\section{Research Process}

\subsection{Research Method}

Based on the theory of musical emotions, this article first studies the differences in creative thinking among testers in different musical environments. Secondly, this article studies whether musical emotions have an impact on divergent thinking. All measurements were processed according to experimental regulations, and experiments were conducted through experiments and interviews to evaluate the emotional feelings caused by different types of music.

\subsection{Research Tools}

\subsubsection{Music sample}

Conduct research through a large number of different categories of music. Use music without lyrics as a sample and avoid lyric music or strongly thematic program music. In the experiment, the experts sorted out the samples, and selected 30 songs with positive emotions and 30 songs with negative emotions.

3.2.2 Russell circular emotion scale

This scale is used to test the tester's feelings after hearing 50 pieces of music. The first emotional dimension includes "pleasant music" that makes people feel delighted, happy and so on, and "sad music" that makes people feel sad, gloomy and so on. The second emotional dimension contains "stimulus music" that makes people feel inspired, aroused, and uplifted and so on, and "calming music that makes people feel calm, peaceful and tranquil 
and so on.

\subsubsection{Divergent thinking measurement}

Divergent thinking pays attention to the thinking process, is not limited by a fixed scope or direction, and explores an unknown thinking process. Based on Gilford's study of divergent thinking, the most famous test for divergent thinking is the extraction of creativity from the concept of wisdom, the measurement tool of the Torrance Tests of Creative Thinking (TTCT).Its inventor was Gilford's assistant, Torrance. The test contains some relatively simple words and graphics as a measure of divergent thinking and other problem-solving skills.

\subsection{Research Objects}

The research objects are randomly selected from students who have applied for innovation projects in Guangzhou University City. Two experiments were conducted on participating students by voluntarily signing up. Experiment 1 is the prediction experiment, and experiment 2 is the formal experiment, supplemented by the open nature research method. The test explores the factors that influence emotional reflection through interviews.

\subsection{Research Procedure}

\subsubsection{Site arrangement and equipment}

A noise-free venue was chosen. Music of 50-70 decibels that is best for human acceptance. The introduction was as follows: Hello everyone, we are going to play 50 different pieces of music now. Please listen carefully. After each paragraph, according to your feelings about the music, check the most suitable points on the following scales. The length of each piece of music is about one minute. Please don't talk or walk around in the experiment. The interval between each piece of music is 30 seconds. We will play the next music after making sure that each subject has made a choice.

3.4.2 Interview

During the interview, the subjects described their feelings. We analyzed the corresponding characteristic attributes of the subject's description of music and emotions, and further understood the music attributes and the feelings of the subjects. The researchers interviewed subjects who had heard the music about their emotional responses. For example, the following question was asked: "How do you feel, why do you feel this way?"If the subject expressed their feelings about the rhythm or volume, the interviewer will continue to ask questions and organize the content according to the recording.

Firstly, we learn about the connection between music and emotion. Before the study, we asked the subjects to cooperate with the researchers to evaluate each piece of music played one by one. We try to understand the differences between college students' emotional responses to music, and the characteristic attributes of music affecting emotions during the experiment.

\subsubsection{TTCT}

This test mainly tested four abilities, namely, fluency, flexibility, originality and elaboration. The test content was divided into three categories. The first category is graphical construction based on a circular stimulus picture, the subject was asked to think about a topic, and then use the graphic as a part of the circular theme to draw freely; the second category is to complete the drawings based on ten pictures of unfinished lines; the third category is to create based on three pairs of parallel lines, and finally gave the name for the creation. Each category of this test lasted for ten minutes. There are four criteria to evaluate this test. Generally, we evaluated the fluency by the total number of stimulus graphs in the test time, and the flexibility by the number of categories reflected by the graph, and the originality by the number of rare graphics in the graph, and the elaboration by the sum of the details in the graph.
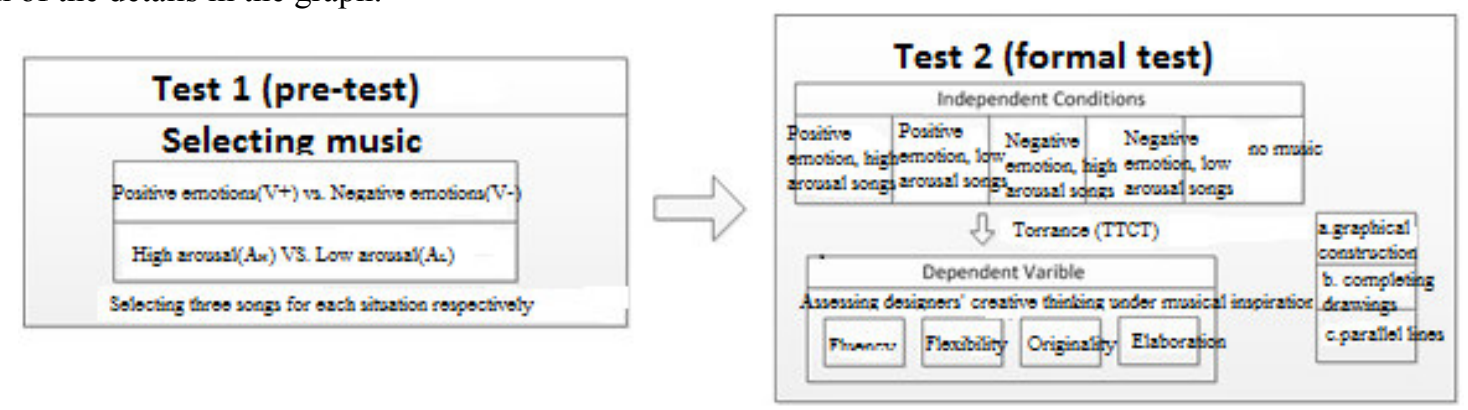

\section{Empirical Results Discussion}

Through empirical research, we find that there is a certain regular relationship between music and emotion. The subject can judge the emotional feeling of music through melody, tone, rhythm and volume. It is found that the two attributes of melody style and timbre are more likely to be judged by the subjects' emotional feeling on the music. We find that the speed of the rhythm is related to the degree of arousal of emotions, and the melody style 
and tone are related to positive and negative emotions.

Then, in five different musical contexts, through the correlation study of the four abilities, we found that the divergent thinking ability scored the highest in the music environment of positive emotion and high arousal. However, in negative emotions, the scores are not high, whether in high arousal or low arousal music environment. However, regardless of the scores in the four groups of music environments, the divergent thinking ability in music environments is higher than the one in no music environment. In other words, the music environment can stimulate divergent thinking. If we compare the four elements of divergent thinking separately, we find that the positive emotional music environment contributes to the improvement of fluency and flexibility; for originality, positive emotions contribute to the originality only in the case of high arousal. Under low arousal conditions, only negative emotions contribute to the originality. Based on the results of the study, we have made the following summary of the entire process of how emotions impact divergent thinking. Therefore, in cultivating college students' divergent thinking ability, schools need to consider the influence of different characteristics of musical emotions for divergent thinking.

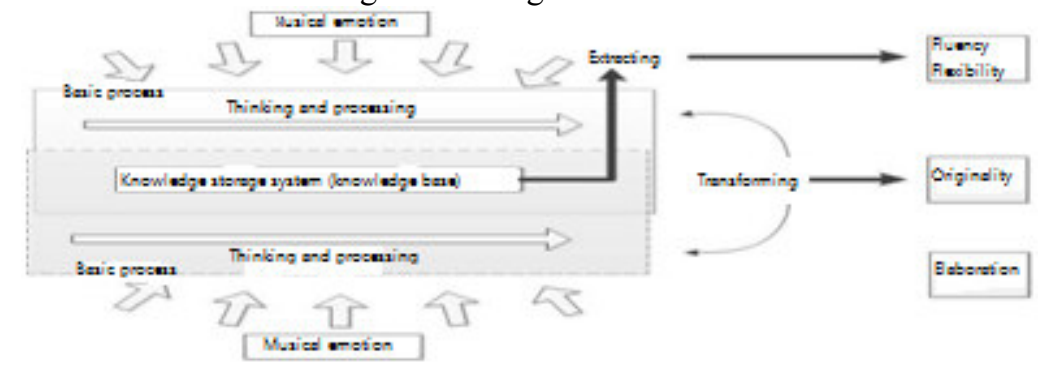

\section{References}

Clark,B.(1988).Growing up gifted(3rd ed.).Columbus. OH:Merrill.

Daubman,1984;Isen,Daubman,\&Nowicki,1987;Isen,Johnson,Mertz,\&Robinson,1985;O’Quin\&Derks,2000;Rich ard\&Kinney,1990;Richard,Kinney,Benet,\&Merzel,1988;Sinnet\&Larsen, 1989

Emery S. Affective, Evaluative, and Collative Responses to Hated and Loved Music [J]. Psychology of Aesthetics, Creativity, and the Arts, (2010), 4(1): 36-46.

Emery, S. The Influence of Emotion, Locus of Emotion and Familiarity upon Preference in Music [J]. Psychology of Music, 2007, 35(3): 499-515.

Garrido, S., Emery, S. Individual Differences in The Enjoyment of Negative Emotion in Music: A Literature Review and Experiment[J]. Music Perception, 2011, 28(3), 279-295

Harris, P.L., Olthof, T., \&Meerum Terwogt, M. Children 's Knowledge of Emotion [J].Journal of Child Psychology and Psychiatry, 1981, 22(3): 247-261.

Lubark,T.i.,\&Getz,I.(1997). Emotion, metaphor, and the creative process. Creativity Research Journal.10(4).285-301

Teresa Lesiuk. The Effect of Preferred Music on Mood and Performance in a High-Cognitive Demand Occupation [J]. Journal of Music Therapy, 2010, 47(2): 137-154.

Watson, D., \& Clark, L. On Traits and Temperament: General and Specific Factors of Emotional Experience and Their Relation to the Five-factor Model [J]. Journal of Personality, 1992, 60: 441-476. 